\title{
Salar Energy
}

And Sustainable Development

Refereed, biannual scientific journal issued by

Center for Solar Energy Research and Studies

\section{The Generation of Typical Meteorological Year for Tripoli, Libya}

\author{
Yosof M. Khalifa ${ }^{1}$, Farag S. Alargt ${ }^{2}$ \\ Centre for Solar Energy Research and Studies, Tajoura, Tripoli-Libya \\ e-mail: ${ }^{1}$ y.m.a.khalifa@csers.ly; 2 fareglarkt@hotmail.com;
}

\begin{abstract}
In this paper a Typical Meteorological Year (TMY) of Tripoli city, the capital of Libya was presented and analyzed using twelve year of measured weather data, this data includes global solar radiation, air temperature and wind speed. The measurements were taken every ten minutes. Finkelstein-Schafer statistical method was applied to analyze the data and obtain the TMY for the site. Typical Meteorological Months (TMMs) were selected by choosing the one with the least deviation from the long-term cumulative distribution function. A close-fit agreement is observed between the generated TMY and the long-term averages. Thus TMY generated will be very useful tool for optimal design and performance evaluation of solar energy conversion systems, heating, wind, and other renewable energy systems to be located in this part of Libya.
\end{abstract}

\section{استنباط السنة النمطية المناخية لمدينة طرابلس ـ ليبيا يوسف خليفتة و فرج الارقط \\ مركز بحوث ودراسات الطاقت الشمسيتــطرابلس-ليبيا}

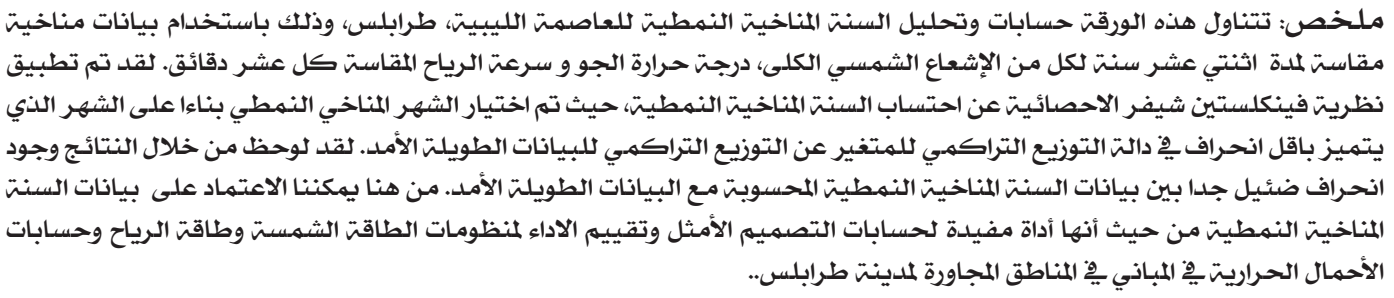

Keywords: Typical Meteorological Year; TMY; Tripoli-Libya; statistical method; Solar radiation; Wind speed, Air temperature 
$\square$

\section{INTRODUCTION}

Recently, renewable energy sources have seen a huge global interest, especially in the field of solar and wind energy. Libya is one of the countries receiving an average global solar radiation of up to $6.58 \mathrm{kWh} / \mathrm{m}^{2} /$ day and an average wind speed reaches about $9 \mathrm{~m} / \mathrm{s}$ at $80 \mathrm{~m}$ above ground level. Libya is located in North Africa, with $1,770 \mathrm{~km}$ of coastline along the Mediterranean and a surface area about 1.7 million $\mathrm{km}^{2}$. Libya is bordered by Egypt from the east, Algeria and Tunisia from the west, and Chad, Niger and Sudan from the south.

Renewable energy sources (wind, solar, hydro-power, etc.) are unlimited, clean, free, and offers many environmental and economic benefits; prediction of the performance of renewable energy systems for a particular location using a computer simulation requires meteorological data covering a period of a whole year. Meteorological data from measurements should be used for this simulation $[1,2,3]$.

A representative database for one-year duration is known as test reference year (TRY) or typical meteorological year (TMY). In other words, TMY can be defined as the tool that provides a standard for hourly data for a period of one year, for any available meteorological parameter, such as global radiation, wind speed, etc. Representing climatic conditions considered to be typical over a long-time period. It consists of the months selected from the individual years and concatenated to form a complete year. Many methods have been made to produce such weather databases for different locations around the world $[1,4,5,6,7]$

Center for Solar Energy Research and Studies (CSERS) is the main renewable energy $\mathrm{R} \& \mathrm{D}$ organization in Libya. It was founded in 1978. CSERS have a meteorological monitoring station installed at the center, solar radiation data and other meteorological parameters have been collected for more than 12 years. This data was used as a database for selecting the (TMY).

In the past, several methodologies for generating TMYs have been reported, such as Sandia method,
Festa- Ratto method, Danish method and others [6], all targeted at selecting single months or years from a long-term typical weather condition. Among the different TMY generation methods, the Sandia method is widely adopted [1,3-14] generated TMYs for different locations with different weather parameters and assigned weighting factors. This methodology has been adopted by different countries: for example, by date of publication, for Latvia [9], Athens, Greece [12], Oman [11], Damascus, Syria [6], Nigeria [3, 7-8], Chile [10], Istanbul, Turkey [14], and Armidale NSW, Australia [14]. Methods in above literatures are in fact similar, the main differences lie in the numbers of daily indices (weather indices) to be included and their assigned weightings $[3,13]$.

For Libya, only one attempt has been founded in the literature for the generation of TMY datasets [15], for which, a TMY for Tajura city was generated using Design Reference Year method, the database used in that study was just 4 years from CSERS database.

In this study, the Finkelstein-Schafer (FS) statistical method is used. As the effect of weighing indices for developing a TMY has been studied [1], it was found that in solar applications, a TMY mainly driven by global solar radiation giving the best performance, and similarly for wind turbine applications its driven by wind speed, and in the applications for cooling and heating were driven by air temperature. Hence for the best accuracy and precision of TMY results, three separated TMYs was computed for wind speed, air temperature and global solar radiation respectively. For every parameter the FS function was computed for each month of every year of the database. and for selection of each month, the month with a minimum value of FS is considered.

The results will be essential for developing solar energy systems, wind energy systems, and for building heating/cooling load calculations in order to facilitate performance comparison of different energy systems in Libya with a low computational time and low space. 
A brief review on the location and the data description will be presented in section 2. Whereas, the method used to generate TMY is illustrated in section 3. The results of the study and the selected TMM for every parameter are presented in section 4. Finally, section 5 summarize the concluding remarks obtained from the current work.

\section{LOCATION AND DATA DESCRIPTION}

The Center for Solar Energy Research and Studies (CSERS) is located at $25 \mathrm{~km}$ East of Tripoli city - in Tajura region. The weather database recorded at the meteorological station of the CSERS covers the period from 2005 to 2016 registered for every 10 minutes.

There were missing and invalid measurements in the data and they were filled as null, as if more than five days measured data were not available in a month, that month is excluded from the database [4]. Table 1. summarize a percentage values of missed data from the database used in this study.

Table (1). Percentage of missed data from CSERS database

\begin{tabular}{|l|l|}
\hline Year & Missed data \\
\hline 2005 & $8.35 \%$ \\
\hline 2006 & $5.63 \%$ \\
\hline 2007 & $9.4 \%$ \\
\hline 2008 & $10.82 \%$ \\
\hline 2009 & $43.45 \%$ \\
\hline 2010 & $8.6 \%$ \\
\hline 2011 & $2.2 \%$ \\
\hline 2012 & $22.28 \%$ \\
\hline 2013 & $12.28 \%$ \\
\hline 2014 & $5.47 \%$ \\
\hline 2015 & $0.85 \%$ \\
\hline 2016 & $0.27 \%$ \\
\hline
\end{tabular}

\section{TMY METHOD}

The approach used for selecting TMYs for a given zone can be summarized as follows: a typical month for each of the twelve calendar months from the long-term data base was chosen and then those
12 months TMMs are concatenated to form TMYs [11].

Finkelstei-Schafer (FS) statistics (FinkelsteinSchafer, 1971) are the common methodology for generating typical weather data. According to these statistics), if a number $n$, of observations of a variable $\mathrm{X}$ are available and have been sorted into an increasing order $\mathrm{X} 1, \mathrm{X} 2, \ldots, \mathrm{Xn}$, the cumulative frequency distribution Function (CDF) of this variable is given by a function $\mathrm{Sn}(\mathrm{X})$ which is defined as follows [1,3-13]:

$S_{n}(x)= \begin{cases}0 & \text { for } x<x_{i} \\ \frac{(k-0.5)}{n} & \text { for } x_{k}<x<x_{k-1} \\ 1 & \text { for } x>x_{n}\end{cases}$

where, $x$ represents the weather index; $\operatorname{Sn}(\mathrm{x})$ is the value of the CDF for the weather index $x$; and $n$ is the total number of elements.

The FS by which comparison between the longterm CDF of each month and the CDF for each individual year of the month was done is given by the equation $[1,3,5]$ :

$$
\mathrm{FS}(\mathrm{y}, \mathrm{m})=\frac{1}{\mathrm{~N}} \sum_{\mathrm{t}=1}^{\mathrm{N}}\left|\mathrm{CDF}_{\mathrm{m}}\left(\mathrm{x}_{\mathrm{i}}\right)-\mathrm{CDF}_{\mathrm{y}, \mathrm{m}}\left(\mathrm{x}_{\mathrm{i}}\right)\right| \ldots \ldots .
$$

Where, $\mathrm{CDF}_{\mathrm{m}}$ and $\mathrm{CDF}_{\mathrm{y}, \mathrm{m}}$ are long-term and short term for the year $\mathrm{y}, \mathrm{CDF}$ of the daily variable $\mathrm{x}$ for month $\mathrm{m}$, respectively; and $\mathrm{N}$ is the number of days of the month.

$\mathrm{FS}(\mathrm{y}, \mathrm{m})$ is then calculated for every year with valid historical values and is ranked in ascending order, then, for each month, the year with minimum value of FS is selected as TMM.

\section{RESULTS AND DISCUSSION}

The database of the meteorological weather parameters recorded by CSERS was analyzed using a MATLAB algorithm to calculate the CDFs for each month and for each meteorological parameter, then the TMM is computed by selecting the month with the minimum value of FS. Three separate TMYs for global solar radiation, wind speed and ambient temperature were generated. 
口

Based on the FS statistics and the meteorological database used in this work, the CDF curves of daily air temperature for the month of October is shown in Figure 1, the CDF of daily temperature for October 2010 is very close to the long-term CDF (best, smallest value of FS statistic), while the CDF of daily temperature for October 2011 is a bit distant from long-term CDF (worst, largest value of FS statistic). Whereas, October 2012 represents the TMM, for which it lies between the two other months.

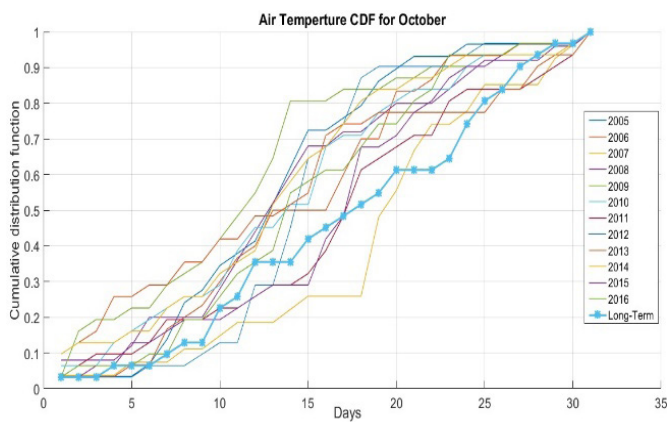

Figure (1). The CDF curves of daily air temperature for October.

For air temperature, Figures 2 and 3 shows the hourly average air temperature for September and November respectively. These figures display a LongTerm (average of database records), TMMs, best month and worst month compared to the long-term curve, it can be seen that, the (TMY) is very close to the (LT) data base for both months; September and November.

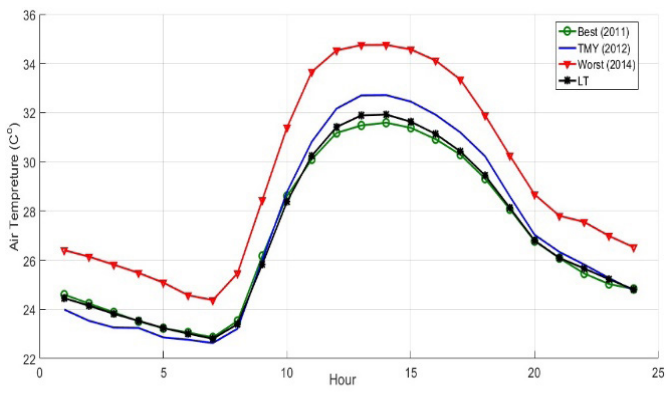

Figure (2). average hourly air temperature for September.

Furthermore, for global solar radiation, figures 4 and 5 shows hourly global solar radiation for
February and September respectively, a good relationship occurs between the (LT) and the (TMY) values for the global solar radiation, however a very small variation were noted.

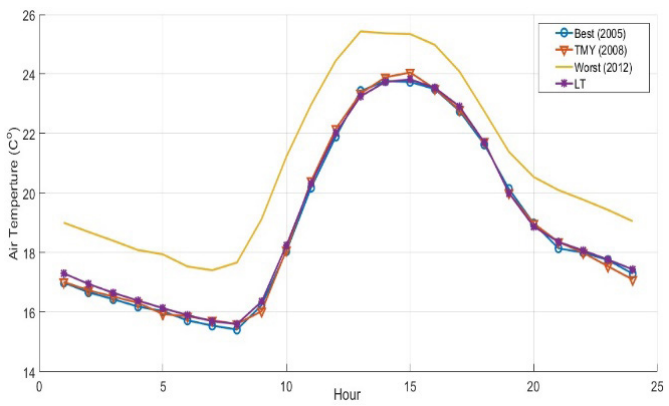

Figure (3). average hourly air temperature for November.

A similar trend with admirable relationships between the (TMY) and the (LT) mean of the global solar radiation were noted. Even though the worst year (WY) follows similar trend to the long term and TMY curves.

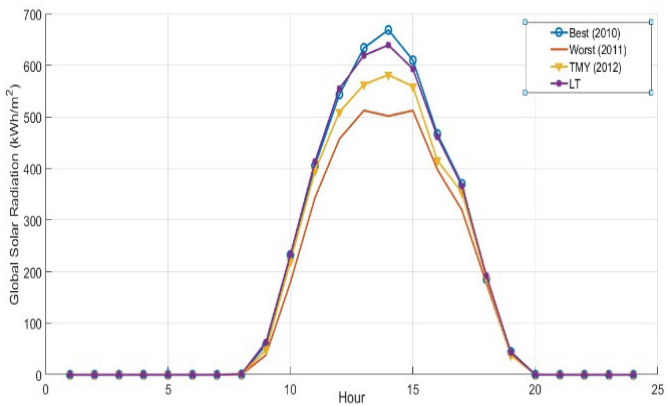

Figure (4). hourly global solar radiation for February.

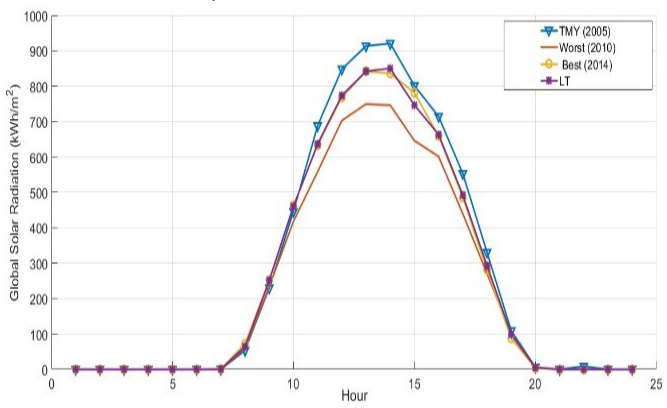

Figure (5). hourly global solar radiation for September. 
Finally, for wind speed figures 6 and 7 shows average daily wind speed for May and November respectively.

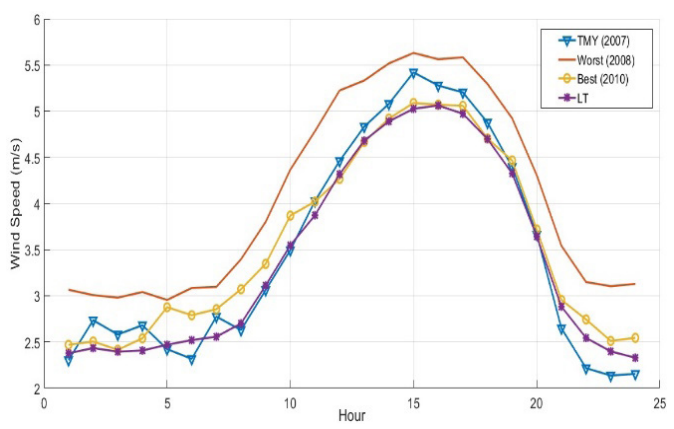

Figure (6). average daily wind speed for May.

A similar manner with admirable relations between the (TMY) and the (LT) mean of the wind speed have been observed. Even though the worst year (WY) follows similar trend to the long term and TMY curves.

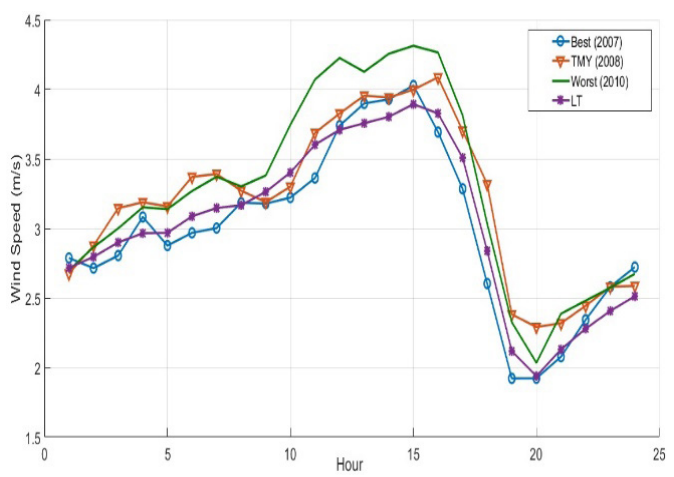

Figure (7). Average daily wind speed for November.

Table 2 shows the result of the TMY for wind speed, solar radiation and air temperature

\section{CONCLUSIONS}

The TMY generated will be very useful tool for optimal design and evaluation of solar energy conversion systems, wind energy conversion systems, and HVAC, and other renewable energy dependent systems to be located within the vicinity of Tripoli. This work is a part of ongoing research work to develop a complete TMY weather in Libya.
Results based on the implementation of FilkensteinSchafer statistical method utilized for the creation of a TMY for Tripoli shows the following:

Table (2). Summary of TMY results

\begin{tabular}{|l|l|l|l|}
\hline \multicolumn{5}{|c|}{ TMY } \\
\hline $\begin{array}{c}\text { Parameter/ } \\
\text { month }\end{array}$ & $\begin{array}{c}\text { Wind } \\
\text { Speed }\end{array}$ & $\begin{array}{c}\text { Solar } \\
\text { Radiation }\end{array}$ & $\begin{array}{c}\text { Air } \\
\text { Temperature }\end{array}$ \\
\hline Jan & 2011 & 2013 & 2011 \\
\hline Feb & 2009 & 2012 & 2008 \\
\hline Mar & 2007 & 2016 & 2014 \\
\hline Apr & 2014 & 2010 & 2007 \\
\hline May & 2007 & 2013 & 2014 \\
\hline Jun & 2006 & 2005 & 2012 \\
\hline Jul & 2016 & 2012 & 2013 \\
\hline Aug & 2010 & 2013 & 2006 \\
\hline Sep & 2006 & 2005 & 2012 \\
\hline Oct & 2012 & 2013 & 2011 \\
\hline Nov & 2008 & 2007 & 2008 \\
\hline Dec & 2007 & 2016 & 2009 \\
\hline
\end{tabular}

- The developed 12 TMMs for wind speed are spread with three TMMs found in 2007 and two in 2006, and the rest is distributed in 2008, 2009, 2010, 2011, 2012,2014, and 2016. Whereas; for global radiation the distribution was as follows; Four TMMs in 2013, tow in 2012, two in 2016, two in 2005, one in 2007 and one in 2010. For ambient temperature, the TMMs was spread with two in 2014, two in 2012, two in 2011, two in 2008, one in 2006, 2007 and 2009.

- The current work represents a first step to developing a full TMY weather database for Libya. As the TMY facilitates the design and performance evaluation of renewable energy systems simulations and building heating and cooling loads.

- It is also concluded that the deviations of the TMY data from long term data are found to be small which means the generated TMYs 
마

can effectively be used instead of the long term averaged and hereafter, weather data processing and computation duration and space can be reduced such calculations.

- There were some missing data, future work will be the calculations of missed data by studying the methods used for filling and the estimations of the missed data.

\section{REFERENCES}

[1]. Georgiou, G., Eftekhari, M, Eames, P, and Mourshed, M. "A study of the effect of weighting indices for the development of TMY used for building simulation", 2013, $13^{\text {th }}$ Conference of the International Building Performance Simulation Association, pp.922-929.

[2]. Pattarapanitchai, S., Tohsing, K., and Pankaew, P. " Generation of Typical Meteorological Year Data Sets for 20 Stations in Thailand" International Conference and Utility Exhibition 2014 on Green Energy for Sustainable Development (ICUE), pp.35-41.

[3]. Ohunakin, O. S., Adaramola, M. S., Oyewola, O. M., and Fagbenle, R. O. "Generation of a typical meteorological year for north-east, Nigeria" Applied Energy, Volume 112, December 2013, pp 152-159.

[4]. Zang, H., Xu, Q. , Du, P., and Ichiyanagi, K. ," A modified method to generate typical meteorological years from the long-term weather database". International Journal of Photoenergy (2012). Article ID 538279 .

[5]. Yang, C., Xu, Q., Xu, X., Zeng, I., and Yuan, X.” Generation of Solar Radiation Data in Unmeasurable Areas for Photovoltaic Power Station Planning" PES General Meeting Conference \& Exposition, 2014 IEEE.

[6]. Skeiker, K." Comparison of methodologies for TMY generation using 10 years data for Damascus, Syria" Energy Conversion and Management, Volume 48, Issue 7, July 2007, pp 2090-2102.
[7]. Ohunakin, O. S., Adaramola, M. S., Oyewola, O. M., Fagbenle, R. O. and Abam, F. I. " A Typical Meteorological Year Generation Based on NASA Satellite Imagery (GEOS-I) for Sokoto, Nigeria”. International Journal of Photoenergy (2014). Article ID 468562 .

[8]. Fagbenle, R. L. "Generation of a test reference year for Ibadan, Nigeria" Energy Conversion and Management, Volume 36, Issue 1, 1995, pp 61-63.

[9]. Martins Ruduks, Arturs Lesinskis," Generation of a typical meteorological year for alūksne, latvia" 5th international conference civil engineering'15 proceedings heat engineering, 2015. pp 71-78.

[10]. Sepúlveda, C., G. Merino, F. Pino. J. Cañumir," Comparison of Methodologies for TMY Generation Using 15 Years Data for Chillan, Chile", IOSR Journal of Engineering, Vol. 04, Issue 09, 2014. pp 24-34.

[11]. S. Pattarapanitchai, K. Tohsing, P. Pankaew," Analysis of Typical. Meteorological Year for Seeb/Muscat Oman" International. Journal of Low. Carbon. Technology",2007. pp.323-338.

[12]. Argiriou, A.; Lykoudis, S.; Kontoyiannidis, S.; Balaras, C. A.; Asimakopoulos, D.; Petrakis, M.; Kassomenos, P," Comparison of methodologies for tmy generation using 20 years data for Athens, Greece" Solar Energy, vol. 66, issue 1,1999. pp. 33-45.

[13]. Yasser Maklad," Generation of an Annual Typical Meteorological Wind Speed for. Armidale NSW,Australia”, IOSR Journal of Engineering, Vol. 04, Issue 07, 2014. pp 09-14.

[14]. Husamettin Bulut," Generation of typical solar radiation data for Istanbul, Turkey" International journal of energy research, Volume 27, 2003, pp :847-855.

[15]. Abdunnabi, M. R., Gumati, F., and Rgaie, A. "Typical meteorological year for the city of tajoura" Journal of solar energy and sustainable development, vol. 1 , no. 1, pp. 1-6, 2012. 